\title{
Smoker's face: an underrated clinical sign?
}

\author{
DOUGLAS MODEL
}

\begin{abstract}
In a prospective survey of patients attending a general medical outpatient clinic roughly half the current cigarette smokers who had smoked for 10 years or more were identified, using defined criteria, by their facial features alone. These facial features, designated "smoker's face," were present in three $(8 \%)$ of those who had smoked cigarettes for 10 years or more in the past and in none of the non-smokers. The association of smoker's face with current smoking that had continued for 10 years or more was significant $(p<0.001)$ and remained after the patient's age, social class, exposure to sunlight, recent change of weight, and estimated lifetime consumption of cigarettes were controlled for. Smoker's face may be a helpful indicator in antismoking campaigns.
\end{abstract}

\section{Introduction}

A relation between smoking and the complexion was first suggested as early as $1856 .^{1}$ Although Daniell pointed out that a relation between cigarette smoking and wrinkling of the face "can be readily confirmed by interested, even though untrained, observers,"' such a relation is not generally acknowledged as a physical sign and is not mentioned in any of the large standard textbooks of medicine, textbooks of physical signs, ${ }^{7}$ or publications about morphology and smoking, ${ }^{\circ}$ smoking and health, ${ }^{4 \cdot 10}$ or smoking and aging. ${ }^{.1}$ Indeed to date there have been only three studies exploring a possible relation between cigarette smoking and wrinkling or other changes in the complexion of the face. In 1965 Ippen and Ippen reported such a relation in German women. ${ }^{12}$ Subsequently in a much larger study from California Daniell reported a similar relation in both men and women. ${ }^{2}$ Later Allen et al challenged Daniell's findings, ${ }^{13}$ but, as Weiss pointed out, when properly interpreted Allen et al's data actually support Daniell's claim. ${ }^{14}$ Having independently formed the impression that in some people cigarette smoking changes the facial features, I carried out a prospective survey to test the hypothesis that in middle age many cigarette smokers can be differentiated from non-smokers by their facial features.

\section{Study population and methods}

The survey included all new patients aged 35-69 attending a general medical outpatient clinic at two hospitals. Younger and older people were excluded as a preliminary survey showed that some years are required for the characteristics under consideration to develop, while in those aged over 70 the changes being studied tend to blur with those due to aging.

Before I considered the clinical problem for which they had been referred, as the patients sat in the waiting area of the clinic they were told that a survey was being conducted, were asked to cooperate, and were then asked by a medical student about their age, dietary and smoking habits, alcohol intake, occupation, and any recent change in weight. Then they were shown into the survey room. So that information should be obtained only from their faces and not from any odour of tobacco or staining of the fingers from nicotine, subjects were assessed in daylight at a fixed distance of $1.5 \mathrm{~m}$ with only their heads and necks visible. I categorised the features of the patient's face, and the decision was noted on the survey sheet without any knowledge of the information gathered by the student other than the patient's age.

Department of Medicine, District General Hospital, Eastbourne BN21 2UD DOUGLAS MODEL, MRCP, consultant physician
On the basis of their occupation patients were divided into non-manua and manual social classes according to the Registrar General's classification of occupations 1980. Subsequently, a postal survey was carried out to collect information about exposure to sunlight. The information gathered in this way was categorised without knowledge of the results of the main part of the survey. Considerable exposure to the sun was defined as living in a sunny climate for 10 or more years, living for three or more months in a sunny climate on at least 10 occasions, or gardening or pursuing some other outdoor pastime such as fishing for at least eight hours a week for three months or more a year over at least 10 years.

\section{DEFINITIONS OF STATE OF SMOKING}

A non-smoker was one who smoked fewer than 10 cigarettes or less than $14 \mathrm{~g}$ tobacco a week or had smoked for less than 10 years, or both. A current smoker was one who within the past year had smoked 10 or more cigarette or $14 \mathrm{~g}$ or more tobacco a week and had smoked for 10 years or more. A past smoker was one who had not smoked within the past year but had smoked 10 or more cigarettes or $14 \mathrm{~g}$ or more tobacco a week for 10 years or more before that.

\section{EFFECTS OF SMOKING ON THE FACE}

Patients were divided into two groups; those with smoker's face and those without smoker's face. Smoker's face was defined as one or more of the following: $(a)$ lines or wrinkles on the face, typically radiating at right angles from the upper and lower lips or corners of the eyes, deep lines on the cheeks, or numerous shallow lines on the cheeks and lower jaw. (b) A subtle gauntness of the facial features with prominence of the underlying bony contours. Fully developed this change gives the face an "atherosclerotic" look; lesser changes show as slight sinking of the cheeks. In some cases these changes are associated with a leathery, worn, or rugged appearance. (c) An atrophic, slightly pigmented grey appearance of the skin. (d) A plethoric, slightly orange, purple, and red complexion different from the purply blue colour of cyanosis or the bloated appearance associated with the pseudoCushing's changes of alcoholism.

The difference in the number of patients with smoker's face between the current smoking group and the non-smoking group was analysed by the $\chi$ test. To examine the possibility that smoker's face was related to smoking via an intermediate factor I also analysed the results by controlling for the following: patient's age, social class, exposure to sunlight, recent change in weight, and estimated lifetime consumption of cigarettes.

\section{Results}

I surveyed 122 patients. With the exception of one Asian man, all were white. Six were excluded as either pipe or cigar smokers. The analysis therefore concerned the remaining 116 patients, of whom 41 were curren cigarette smokers, 37 past smokers, and 38 non-smokers. None of the patients was being treated for any dermatological condition of the face.

Table I shows that smoker's face was present in $19(46 \%)$ current smokers, three past smokers, and none of the non-smokers. The association of smoker's face with current cigarette smoking was highly significant $\left(\chi^{2}=23\right.$, $\mathrm{p}<0.001$ ).

Most patients with smoker's face were men; 17 of the 28 men and only two of the 13 women who currently smoked cigarettes. Among the men the association of smoker's face with current smoking was highly significant $\left(\chi^{2}=18, p<0.001\right)$.

The average ages of the current smokers with and without smoker's face were similar-that is, 53.8 and 52.0 years, respectively. Several patients with smoker's face were fairly young: of the 15 current smokers aged less than 50 years, five had smoker's face. The three past smokers with smoker's face had stopped smoking two, five, and eight years previously.

Information about exposure to the sun was available for 108 subjects. Table II shows that neither social class nor exposure to the sun accounted for the relation between smoking habits and smoker's face. Nor was smoker's 
TABLE I-Smoker's face and state of smoking

\begin{tabular}{|c|c|c|c|c|c|c|}
\hline & \multicolumn{2}{|c|}{$\begin{array}{c}\text { Non- } \\
\text { smokers }\end{array}$} & \multicolumn{2}{|c|}{$\begin{array}{c}\text { Past } \\
\text { smokers }\end{array}$} & \multicolumn{2}{|c|}{$\begin{array}{l}\text { Current } \\
\text { smokers }\end{array}$} \\
\hline & No & $\begin{array}{c}\text { Average } \\
\text { age } \\
\text { (years) }\end{array}$ & No & $\begin{array}{c}\text { Average } \\
\text { age } \\
\text { (years) }\end{array}$ & No & $\begin{array}{c}\text { Average } \\
\text { age } \\
\text { (years) }\end{array}$ \\
\hline $\begin{array}{l}\text { Smoker's face present } \\
\text { Smoker's face absent }\end{array}$ & 38 & $54 \cdot 8$ & $3^{3^{*}}$ & $\begin{array}{l}60 \cdot 0 \\
61 \cdot 1\end{array}$ & $\begin{array}{l}19 \\
22\end{array}$ & $\begin{array}{l}53 \cdot 8 \\
52 \cdot 0\end{array}$ \\
\hline Total & 38 & & 37 & & 41 & \\
\hline
\end{tabular}

*Two women, one man.

TABLE II-Exposure to the sun, social class, and smoker's face in current cigarette smokers and non-smokers

\begin{tabular}{lcc}
\hline & $\begin{array}{c}\text { No (\%) of smokers } \\
\text { with smoker's face }\end{array}$ & $\begin{array}{c}\text { No (\%) of non-smokers } \\
\text { without smoker's face }\end{array}$ \\
\hline $\begin{array}{l}\text { Non-manual class } \\
\text { Manual class }\end{array}$ & $7(47)$ & $27(100)$ \\
Exposed to sun & $12(46)$ & $11(100)$ \\
Not exposed to sun & $7(52)$ & $16(100)^{\star}$ \\
\hline
\end{tabular}

*Information not available on two patients in these groups.

face related to a recent change in weight or to the number of cigarettes smoked in the patient's lifetime, roughly estimated as the number of cigarettes currently smoked a day times the number of years of smoking. Thus among the 19 current smokers with smoker's face 13 had steady weight and two were heavier and four lighter than a year before. Similarly, although the estimated lifetime consumption of cigarettes among the smokers with smoker's face (mean 669 (SD 376) cigarette years) was slightly greater than that among those without smoker's face (mean 542 (363) cigarette years), the difference was not significant.

The diagnoses among the patients were varied as might be expected in a

Smokers' faces: answers

\begin{tabular}{l|} 
Non-smoker \\
67 year old woman \\
\\
A
\end{tabular}
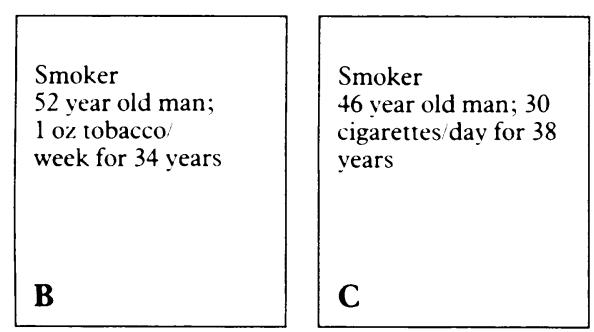

\begin{tabular}{l|}
\hline Non-smoker \\
David Simpson, \\
director of Action \\
on Smoking and \\
Health \\
\\
D \\
\hline
\end{tabular}
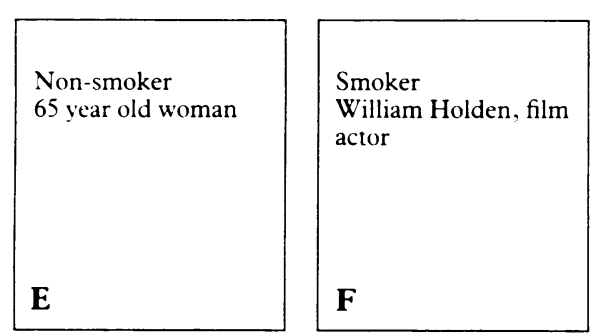

\begin{tabular}{|l|} 
Smoker \\
62 year old woman; 20 \\
cigarettes/day for 40 \\
years
\end{tabular}

general medical outpatient clinic. No association was evident between smoker's face and diseases either related (eight cases) or unrelated (14 cases) to smoking.

\section{Discussion}

This survey confirms the findings of Ippen and Ippen ${ }^{12}$ and Daniell $^{2}$ that cigarette smoking causes readily recognisable wrinkling and other changes to the faces of many people. Daniell's large study, however, was mainly concerned with grading the degree of facial wrinkling for the whole of his study population and relating the various grades to the number of cigarettes smoked a day. By contrast this study was concerned with identifying only the subgroup of people within a population who fulfil the defined criteria of a clinical sign allowing them to be picked out as cigarette smokers. Perhaps the reasons that these changes have not been more generally associated with smoking is that smoker's face is fairly common and has been accepted as part of the normal appearance of the face.

One possible criticism of this work is that assessing faces in this way is necessarily subjective. Similar subjective limitations, however, are accepted in the assessment of physical signs such as hypothyroid facies, depression as an expression of the face, cyanosis, anaemia, and clubbing of the finger nails. Moreover, just as Daniell found that children can learn to recognise smoker's face, I found that nurses and medical students quickly learn to recognise the sign, which confirms that it really exists.

The results reported here were obtained in patients attending a general medical outpatient clinic in the south east of England. Two important qualifications result from this. The first is that such a group of people is highly selected, and that the prevalence of smoker's face generally may be different from that reported here. Thus, although smoker's face was found in subjects from all social classes, the numbers within each group were too small to estimate its prevalence in smokers from each class. Similarly, because only one person in the survey was not white it was not possible to comment on the observation of Allen et al that regardless of whether or not they smoke wrinkling does not occur in black Americans. ${ }^{13}$ The second qualification is that this survey was conducted in a cool, temperate climate where the power of the sun is fairly weak. In other parts of the world where race, exposure to the sun, and nutrition are different, the criteria for smoker's face may be rather different as it is generally agreed that sunlight damages the skin of white people. ${ }^{15}$ Thus Daniell, reporting from sunny California, found that smoking and exposure to the sun each separately caused wrinkling of the face and that together they had a considerably greater effect. ${ }^{2}$

Two possible explanations arise for the observation that so few past smokers had smoker's face: either they had had smoker's face and it had disappeared when they stopped smoking or they were smokers who had never had smoker's face. A longitudinal survey of people who stop smoking would be required to decide this point. Likewise, a further study would be necessary to investigate my impression that obesity tends to obscure smoker's face, presumably by stretching and filling out lines on the face and also filling out the cheeks. Conceivably it was because of weight gain that so few past smokers had smoker's face.

In this survey only four people admitted to having 25 or more alcoholic drinks a week, and only one of these was a current smoker with smoker's face. His face was lined rather than plethoric. It therefore seems unlikely that smoker's face was confused with the plethora of alcoholism.

How does smoking bring about the observed changes? In some ways smoker's face resembles an aging process, but on the other hand, the similarity in the average ages of the current smokers with and without smoker's face and the fact that so many of the people with smoker's face were fairly young indicate that smoker's face is not simply a symptom of age. The changes in the colour and quality of the skin suggest a toxic process. Recently Klemp et al and Reus et al showed that smoking reduces the circulation to the skin in man $^{16}$ and nude mice ${ }^{17}$ respectively. Perhaps biochemical and histological investigations would elucidate other changes. Likewise the contribution of any genetic factor would need further investigation. 
Although the development of noticeable lines on the face is usually associated with smoking, this is not always so. Although no such persons were encountered during this survey, non-smokers are occasionally encountered with lined faces suggestive of smoker's face. These people tend to be women and although their faces are lined, their complexions are usually sufficiently clear to suggest that in fact they are either non-smokers or past smokers.

Apart from being clinically important in the documentation of a patient the fact that smoking can affect the face so profoundly is important because it is so readily appreciated by patients themselves. In my experience many people notice the ravages of smoking for the first time when it is pointed out to them that they can be identified as smokers by their faces alone. Properly explained and perhaps supported by posters bearing photographic examples, the concept of smoker's face might be helpful in antismoking campaigns.

I thank Mr Richard Wilkinson, University of Sussex, for statistical advice and help with the manuscript, Mrs M Kinnear for secretarial help, and medical students Mr O R Saguil, Mr R Tasharofi, and Mr F Hamati for help with collection of the data.

\section{References}

1 Solly S. Clinical lectures on paralysis. Lancet 1856;ii:641-3.

2 Daniell HW. Smoker's wrinkles: a study in the epidemiology of "crow's feet." Ann Intem Med 1971;75:873-80.

3 Cecil RL. Textbook of medicine. 16th ed. Philadelphia: WB Saunders, 1982.

4 Hart FD, ed. French's index of differential diagnosis. 11 th ed. Bristol: John W'right and Sons, 1979

5 Isselbacher $\mathrm{KJ}$, ed. Hamson's principles of internal medicine. 10th ed. New York: McGraw-Hil Book Company, 1983.

6 Weatherall DJ, Ledingham JGG, Warrell DA, eds. Oxford texthook of medicine. Oxford: Oxfor University Press, 1983.

Ogilvie C. Chamberlain's symptoms and signs in clinical medicine. Bristol: John W'right and Sons, 1980

8 Seltzer CC. Morphological constitution and smoking. Arch Environ Health. 1968;17:143-7.

9 Surgeon General. Smoking and health: a report of the surgeon general. Washington: US Department of Health, Education and Welfare, 1979.

10 Royal College of Physicians. Smoking or health. London: Pitman, 1983.

11 Bossé R, Rose CL. Smoking and ageing. Lexington: Lexington Books, 1984

12 Ippen $\mathrm{M}$, Ippen $\mathrm{H}$. Approaches to a prophylaxis of skin ageing. Fournal of the Society of Cosmetic Chemists 1965:16:305-8.

13 Allen HB, Johnson BL, Diamond SM. Smoker's wrinkles? fAMA 1973;225:1067-9.

13 Allen HB, Johnson BL, Diamond SM. Smoker's wrink
14 Weiss W. Smoker's wrinkles. FAMA 1973;226:788.

15 Kligman AM. Early destructive effect of sunlight on human skin. FAMA 1969;210:2377-80.

16 Klemp P, Staberg B, Thomsen K. Skin circulation in regular smokers. Ugeskr Lager 1982;144:1604-6.

17 Reus WF, Robson MC, Zachary L, Heggers JP. Acute effects of tobacco smoking on blood flow in the cutaneous micro-circulation. Br f Plast Surg 1984;37:213-5.

(Accepted 10 fulv 1985)

要

\title{
DISH at Merton Priory: evidence for a "new" occupational disease?
}

\author{
TONY WALDRON
}

Disseminated idiopathic skeletal hyperostosis (DISH) is a disease of considerable antiquity'; it rarely declares its presence to the clinician before the patient is aged 40 but thereafter becomes increasingly prevalent so that after the age of 70 about $10 \%$ of men and $7 \%$ of women can be found with the condition. ${ }^{2}$ I present here some evidence to suggest that in times past the disease was particularly common among those following a religious life and question whether it might have been related in part to that occupation.

The clinical material that forms the basis of the study comes from Merton Priory in Surrey. This was one of the earliest of the Augustinian houses, founded in 1140; it shared in the common fate of the monasteries during the reign of Henry VIII and was dissolved and demolished in 1540 . The site was used much later for industrial purposes: a calico bleaching trench was dug across it in the latter part of the eighteenth century and Liberty's used part of the site for dying material in the nineteenth. In 1868 a railway line was built across the chapter house. It was removed in 1975, and the site was excavated between 1976 and 1978; most of the area is now occupied by industrial units.

\section{Discoveries at Merton Priory}

During the excavations skeletons were recovered from within the chapter house and from the canon's cemetery to the east of the chapter house. There was a total of 35 more or less complete burials, but some of the graves contained small numbers of intrusive bones (a legacy of the many disturbances that the site had suffered), and in one case there were clearly two burials within one grave. Wherever possible the intrusive bones were matched to the appropriate skeleton, after which it became apparent that the bones from at

London School of Hygiene and Tropical Medicine, London WC1E 7HT TONY WALDRON, MB, MRCP, senior lecturer in occupational medicine least seven bodies were present in addition to the 35 burials. There was evidence, therefore, for at least 42 people most of whom should have been priors, although this was certainly not the case for the one female skeleton present. She was presumably a benefactress of the priory who had wished to be buried within its confines.

Among the burials three were found with changes consistent with spinal hyperostosis (fig 1). ${ }^{3}$ Each of these skeletons also showed extraspinal lesions of the type noted by Resnick et al often to accompany the lesions in the spine. ${ }^{+}$There were eight other burials in which extraspinal hyperostoses were present. In three of these the

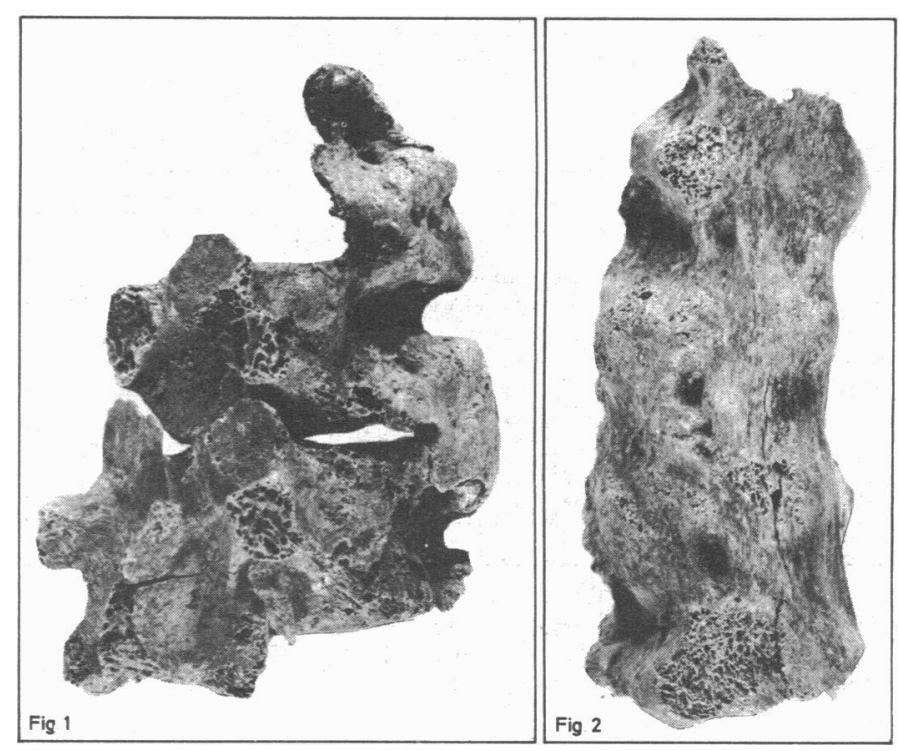

FIG 1-Lateral view of fused thoracic vertebrae from Merton Priory. Hyperostoses are seen on right hand side. FIG 2-Anterior view of fused thoracic vertebrae from Merton Priory. Bodies of vertebrae are extensively fused; there are no exostoses. 